\title{
TOXICOMANIA: A DROGA, O SUJEITO E A PSICANÁLISE
}

\author{
TOXICOMANÍA: LA DROGA, EL SUJETO Y EL PSICOANÁLISIS
}

TOXICOMANIA: DRUGS, SUBJECT AND PSYCHOANALYSIS

\author{
Rafaela Gonçalves de Jesus LAMEGO ${ }^{1}$ \\ Lavínia Carvalho BRITO²
}

RESUMO: A partir de uma revisão da literatura como método de pesquisa, este trabalho pretende apontar os caminhos tradicionalmente percorridos para tratar a problemática do consumo de drogas - tão lesivo e presente na atualidade - assim como os caminhos que podem ser explorados a partir da psicanálise. Analisaremos os termos comumente relacionados ao consumo de drogas, para que possamos distinguir as características que levam os psicanalistas a assumirem o termo toxicomania e não outro qualquer, enfatizando a relação sujeito-droga. Trataremos da sua relação com as estruturas clínicas - neurose, psicose e perversão - com o mal-estar destacado por Freud e com o conceito lacaniano de gozo, objetivando expor a leitura psicanalítica da toxicomania. Com base nos resultados da pesquisa, concluímos que a psicanálise pode contribuir de forma incisiva no tratamento dos toxicômanos, uma vez que este referencial enxerga para além do toxicômano, um sujeito, e se propõe a operar junto a ele.

PALAVRAS-CHAVE: Toxicomania. Psicanálise. Mal-estar. Gozo.

RESUMEN: A partir de una revisión de literatura como método de investigación, este trabajo tiene como objetivo señalar los caminos tradicionalmente recorridos para abordar el problema del consumo de drogas, tan dañino y presente en la actualidad, así como las formas que se pueden explorar desde el psicoanálisis. Analizaremos los términos comúnmente relacionados con el uso de drogas, de manera que podamos distinguir las características que llevan a los psicoanalistas a asumir el término toxicomanía y no cualquier otro, poniendo énfasis en la relación sujeto-droga. Abordaremos su relación con las estructuras clínicas neurosis, psicosis y perversión- con el malestar destacado por Freud y con el concepto lacaniano del goce, con el objetivo de exponer la lectura psicoanalítica de la toxicomanía. Con base en los resultados de la investigación, concluimos que el psicoanálisis puede hacer un aporte incisivo al tratamiento de los adictos a las drogas, ya que este marco mira más allá del adicto, un sujeto, y se propone operar con él.

PALABRAS CLAVE: Toxicomanía. Psicoanálisis. Malestar. Goce.

${ }^{1}$ Centro Universitário de Barra Mansa (UBM), Barra Mansa - RJ - Brasil. Graduada no curso de Psicologia. ORCID: http://orcid.org/0000-0001-9181-6248. E-mail: lamegopsic@gmail.com

${ }^{2}$ Centro Universitário Geraldo Di Biasi (UGB), Rio de Janeiro - RJ - Brasil. Docente no curso de Psicologia UBM. Mestrado em Psicanálise (UERJ). ORCID: http://orcid.org/0000-0002-6639-4458. E-mail: laviniacbn@gmail.com 
ABSTRACT: Based on a review of the literature as a research method, this paper aims to point out the paths traditionally traveled to deal with the problematic of drug consumption so harmful and present today - as well as the paths that can be explored from psychoanalysis. We will analyze the terms commonly related to drug consumption, so that we can distinguish the characteristics that lead psychoanalysts to assume the term toxicomania and not any other, emphasizing the subject-drug relationship. We will treat their relationship with clinical structures - neurosis, psychosis and perversion - with the malaise highlighted by Freud and with the Lacanian concept of jouissance, aiming to expose the psychoanalytic reading of toxicomania. Based on the results of the research, we conclude that psychoanalysis can contribute in an incisive way to the treatment of drug addicts, since this reference sees beyond the drug addict, a subject, and proposes to operate with him.

KEYWORDS: Toxicomania. Psychoanalysis. Malaise. Enjoyment.

\section{Introdução}

Este artigo parte de uma revisão da literatura concernente ao tema da toxicomania, pelo viés da psicanálise. Pretende-se apontar quais os caminhos tradicionalmente percorridos para tratar da problemática do consumo de drogas - tão lesivo e tão presente na atualidade assim como os caminhos que podem ser explorados a partir da psicanálise.

Num primeiro momento, apresentaremos, brevemente, a compreensão que a psicanálise tem sobre o tema da pesquisa. Tal concepção diferencia-se do método científico na medida em que destaca a posição do sujeito do inconsciente na dinâmica clínica e sua consequente importância na prática de pesquisa privilegiada neste trabalho.

Analisaremos os termos comumente relacionados ao consumo de drogas, para que possamos distinguir as características que levam os psicanalistas a assumirem o termo toxicomania e não outro qualquer. Seguiremos apresentando o fenômeno da toxicomania, situando-o no campo da psicanálise e enfatizando a relação sujeito-droga.

Em seguida, vamos apontar a vertente escolhida para abordar a toxicomania dentro dos fundamentos teóricos da psicanálise. Trataremos das questões estruturais deste fenômeno na leitura de diversos autores. Sua relação com as estruturas clínicas - neurose, psicose e perversão - com o mal-estar freudiano, e com o conceito lacaniano de gozo.

A droga enquanto um objeto de consumo é abordada pelos autores referenciados em uma perspectiva lacaniana. O conceito de gadget será indicado em sua relação com a interferência do saber científico no mundo. Tal interferência será apresentada como responsável por possibilitar a inserção da droga no campo do gozo. Assim, será introduzido a função mais-de-gozar, referente à toxicomania. 
Serão mencionadas referências freudianas encontradas na obra ' $O$ mal-estar na civilização', na qual Freud afirma que o propósito e a ambição de todo ser humano, conforme suas próprias ações denunciam, é ser feliz e assim permanecer. Ele formula que:

O que chamamos de felicidade no sentido mais restrito provém da satisfação (de preferência, repentina) de necessidades represadas em alto grau, sendo, por sua natureza, possível apenas como uma manifestação episódica (FREUD, 1930, p. 49).

A felicidade acaba sendo experimentada em circunstâncias menos frequentes do que gostaríamos devido aos obstáculos que a sociedade, com suas leis, ergue à realização dos nossos desejos. Em contrapartida, a infelicidade e o sofrimento são experimentados muito mais facilmente. Diante dessa dinâmica: por um lado visando à felicidade, por outro, tentando evitar o sofrimento, o consumo de drogas se apresenta como uma alternativa, uma medida paliativa frente ao mal-estar, como denominou Freud.

Finalmente, indicaremos as possíveis contribuições que a psicanálise, enquanto campo de saber, pode trazer no enfrentamento do atual e devastador quadro de uso abusivo de drogas.

\section{A pesquisa}

Antes de explorarmos o tema deste trabalho, é importante aludir à questão da pesquisa em psicanálise. Tal questão se apresenta como uma singularidade do saber psicanalítico em comparação com o saber científico.

A pesquisa em psicanálise possui características próprias e específicas que a diferenciam do método científico. Elia (2000) indica que os motivos dessa diferenciação baseiam-se nas relações que a psicanálise mantém com a ciência. Segundo ele, a psicanálise teria se derivado da ciência, no entanto, sem se reduzir a ela. Tendo operado um rompimento discursivo em que a noção de sujeito é a chave elementar. Acerca disso o autor afirma:

[...] que a psicanálise não constitui simplesmente um 'saber' a mais, entre outros, a integrar o rol daquilo que, a partir de uma velha discussão com ares epistemológicos, seriam as ciências (da "natureza" ou da "cultura") ou o campo dos saberes ditos não-científicos...Para nós, e seguindo Lacan, que foi quem o demonstrou, a psicanálise constitui um saber inteiramente derivado porém não integrante do campo cientifico, porquanto resulta de uma operação de 'subversão' desse campo pelo viés do sujeito [...] (ELIA, 2000, p. 21). 
O sujeito com o qual a ciência opera é descrito pelo autor como sem qualidade alguma, um sujeito suposto pelo significante, via pela qual a ciência trata o real pelo simbólico. Contudo, esse sujeito não está incluído em todos os processos científicos. O sujeito é ejetado de seu campo operatório para que ela, a ciência, possa constituir-se como um saber conceitual e matematizado sobre o real empírico. Assim, este saber supõe um sujeito, entretanto, não o coloca em questão, não opera sobre ele (ELIA, 2000).

Todavia, o autor faz referência à Lacan ao afirmar que, derivando da ciência, a psicanálise também opera com um sujeito sem qualidades, portanto, este não pode ser senão o sujeito da ciência. Porém, ao incluir esse sujeito em toda a extensão de seu campo de experiência pela via do inconsciente, a psicanálise promove uma subversão, retirando-o da condição de excluído própria ao sujeito da ciência. Com isso, o sujeito da psicanálise só pode ser incluído como sujeito do inconsciente (ELIA, 2000).

A respeito do sujeito do inconsciente, Elia nos diz que não se trata de um sujeito histórico, empírico, composto de características psicológicas, sociais, políticas e ideológicas. Ele vai afirmar que: "Enquanto tal, ele é sem atributos, e trata-se, na experiência analítica, de reconstruir os modos pelos quais ele construiu, sintomaticamente, a imensa floresta de valores, identificações, traços de pertinência social, política ou ideológica, aspectos psicológicos etc.” (ELIA, 2000, p. 26).

$\mathrm{O}$ autor afirma que o método é o que caracteriza o modo próprio de se conceber e fazer pesquisa em psicanálise. Como foi apresentado acima, uma das principais diferenças que a pesquisa em psicanálise encerra é a inclusão do sujeito em todos os processos, como no saber teórico, na prática clínica, na atividade de pesquisa etc.

A partir dessa perspectiva, conclui-se que toda pesquisa em psicanálise será, inevitavelmente, uma pesquisa clínica (ELIA, 2000).

A relação inerente com o inconsciente é uma dimensão fundamental que a pesquisa possui na prática analítica (ELIA, 2000). Com isso, o autor aponta que:

Toda pesquisa em psicanálise é clínica porque, radical e estruturalmente, implica que o pesquisador-analista empreenda sua pesquisa a partir do lugar definido no dispositivo analítico como sendo o lugar do analista... (ELIA, 2000, p. 23).

Um lugar que deve ser de escuta e de causa para o sujeito, pressupondo o ato analítico e o desejo do analista (ELIA, 2000).

Assim, não se fala em "pesquisa de campo" na psicanálise, pois isso pressupõe a existência de outras modalidades de pesquisa que não seriam "de campo" e sim "teóricas". O 
que existe é um "campo de pesquisa", o inconsciente, no qual o sujeito está incluso. "Por isso, a clínica, como forma de acesso ao sujeito do inconsciente, é sempre o campo da pesquisa" (ELIA, 2000, p. 23). Prossigamos a partir desta compreensão!

\section{Toxicomania, o significante}

Assumir o termo toxicomania, e não algum outro, como dependência química ou drogadição, não é uma escolha aleatória e desprovida de sentido.

Como podemos encontrar na pesquisa realizada por Queiroz et al. (2019), a dependência química é compreendida como um transtorno mental e comportamental, assim como encontramos nas definições de manuais como o CID-10, e o DSM-V. Embora seja o mais utilizado, deve ser destacado que esse termo pode gerar uma compreensão que prioriza o fator fisiológico em que uma substância química causa a dependência, alimentando a concepção de uma doença pela qual o objeto droga é o responsável. A problemática presente nesta concepção também é ressaltada pelos autores:

Por um lado, para que um tratamento seja possível, o dependente químico precisa ter a consciência de que é portador de uma doença crônica e, por conseguinte, da necessidade do tratamento. Por outro lado, existe a dificuldade de responsabilizar moralmente o dependente químico por seus atos cometidos sob a influência de substância psicoativa, uma vez que ele é portador de uma doença crônica (QUEIROZ et al., 2019, p. 02).

A drogadição por sua vez, tem, em sua raiz etimológica, um caráter de submissão a um dono, sendo compreendida como uma relação de escravidão entre o sujeito e o objeto, seja este uma droga ou outro objeto qualquer (QUEIROZ et al., 2019). “A drogadição tem sido abordada por meio de duas perspectivas dominantes no Brasil: a da saúde - na qual o drogadito é um doente -; e a jurídica - na qual ele é um criminoso" (QUEIROZ et al., 2019, p. 05).

Ao tratar desse fenômeno, interessará à psicanálise o seu nível mais radical, que vem a ser classificado como toxicomania, “... o termo toxicomania advém do discurso proferido pela psiquiatria, que, em meados do século XIX, passa a considerá-lo como categoria clínica específica, relacionada à inclinação impulsiva e aos atos maníacos" (SANTIAGO, 2000 apud CARLOS; TÓTOLI, 2017, p. 126).

Pode-se dizer que a toxicomania refere-se à possibilidade de, através do uso de determinada substância psicoativa, encontrar a satisfação completa e então libertar-se de qualquer sofrimento, seja físico ou psíquico, que aflija o sujeito toxicômano. 
A relação do toxicômano com o objeto-substância se impõe sobre a relação simbólica entre o sujeito e o Outro, e é precisamente isso que confere ao sujeito uma ilusão de estar completo, de se realizar sem a intervenção do Outro simbólico (MARCOS E TÓTOLI, 2017, p. 130).

Segundo Queiroz et al. (2019), o uso desse termo denota ainda, uma relação de exclusividade entre o sujeito e a droga, o que também leva a um a relação de escravidão e uma consequente deterioração das relações sociais. "Assim, a toxicomania porta uma busca por alívio para certo mal-estar; no entanto, ela encerra um aprisionamento na relação com a droga" (QUEIROZ et al., 2019, p. 05).

Encontramos em O Mal-Estar na Civilização, referências que justificam essa busca, Freud (1930, p. 48) afirma ali que: “A vida, tal como a encontramos, é árdua demais para nós; proporciona-nos muitos sofrimentos, decepções e tarefas impossíveis. A fim de suportá-la, não podemos dispensar as medidas paliativas”. É aí então que a toxicomania entraria, como uma dessas medidas.

Tais medidas se configuram como saídas para o mal-estar, são meios de conseguirmos extrair algum prazer da vida. As drogas, substâncias tóxicas que agem no corpo, alterando sua química, são apontadas por Freud (1930) como um dos métodos mais interessantes para se evitar o sofrimento.

Segundo Freud (1930), o sofrimento, enquanto uma sensação, só existe na medida em que é sentido, e isso só ocorre em decorrência de determinados modos pelos quais o organismo está regulado. Esta característica é o que confere ao método da intoxicação química um lugar de destaque dentre as medidas paliativas, pois influenciam diretamente o organismo, provocando uma insensibilidade diante do sofrimento. Sobre isso o autor destaca que:

O mais grosseiro, embora também o mais eficaz, desses métodos de influência é o químico: a intoxicação. Não creio que alguém compreenda inteiramente o seu mecanismo; é fato, porém, que existem substâncias estranhas, as quais, quando presentes no sangue ou nos tecidos, provocam em nós, diretamente, sensações prazerosas, alterando, também, tanto as condições que dirigem nossa sensibilidade, que nos tornamos incapazes de receber impulsos desagradáveis (FREUD, 1930, p. 50).

Freud (1930, p. 50) ressalta ainda que "O serviço prestado pelos veículos intoxicantes na luta pela felicidade e no afastamento da desgraça é tão altamente apreciado como um benefício, que tanto indivíduos quanto povos lhes concederam um lugar permanente na economia de sua libido". 
Tais veículos são responsáveis tanto por uma produção instantânea de prazer, como por certa independência do mundo externo, dado que com a assistência desse "amortecedor de preocupações" - termo usado por Freud (1930) - torna-se possível afastar-se da pressão da realidade, seja em qualquer ocasião, buscando refúgio num mundo próprio, onde é possível se sentir melhor.

Por fim, ele destaca que é nessa última propriedade que as substâncias intoxicantes assumem sua capacidade de causar danos, demonstrando seu perigo. Em termos freudianos, "são responsáveis, em certas circunstâncias, pelo desperdício de uma grande quota de energia que poderia ser empregada para o aperfeiçoamento do destino humano" (FREUD, 1930, p. $50)$.

Como pode ser observado, dependendo do modo como se aborda a questão, pode- se promover uma dicotomia entre droga e sujeito, em que a responsabilidade pelo consumo pode ser isolada em cada um dos envolvidos. Oposto a isso, uma perspectiva que valorize a interação entre ambos, considerando aspectos particulares de cada sujeito e as propriedades da droga é o que interessa particularmente a esta pesquisa, uma vez que esses aspectos são importantes, pois influenciam na direção do tratamento que será adotado.

Dos três termos citados, a drogadição e a toxicomania são os que apresentam essa perspectiva e por tanto valorizam a relação do sujeito com a droga. No entanto, possuem diferenças, como Pereira (2008, p. 05) nos diz:

Há certa consonância quanto à diferença entre usuário de drogas e toxicômano. O usuário é aquele que introduz a droga numa série de objetos, fazendo dela apenas mais um objeto de consumo (cerveja, cigarro, café, remédio etc.). "O toxicômano, de outro modo, usa a droga como um objeto exclusivo que impede qualquer outro laço social, estabelecendo uma relação de exclusividade com ela".

Há então, uma possível correlação entre o usuário de drogas e a drogadição, sendo o usuário um drogadito, que introduz o consumo de drogas dentre outros objetos de consumo, mas que consegue manter laços sociais, mesmo que de forma frágil.

O uso do termo adições, com sua ampla gama e espectro, em relação aos objetos do consumo, denota o cerne das inúmeras patologias do ato, como o jogo, a comida, a internet, bem como outras práticas aditivas e suas compulsões (FARIA, 2016, p. 55).

O usuário é aquele que pode consumir a droga de forma regular ou esporadicamente, valendo-se dela tanto para obter prazer como para aliviar-se em momentos de angústia. Contudo, a substância não se torna a principal razão da vida do sujeito. Não apresenta, 
portanto, a dimensão compulsiva que é característica dos toxicômanos (ALBERTI et al., 2003).

O recurso às drogas se apresenta como uma saída diante do mal-estar, o sujeito recorre à substância quando algo se constitui como intolerável e não pode ser simbolizado (ALBERTI et al., 2003).

Não se deve, portanto, se ater ao objeto droga. Quando se parte do ponto de vista psicanalítico, especialmente sob orientação lacaniana, é fundamental que a singular relação que cada sujeito estabelece com a mesma seja priorizada, procurando sempre localizar a função que a droga ocupa na economia psíquica de cada sujeito. Apostar no significante toxicomania faz valer essa orientação, onde o sujeito é sempre responsável por seu modo de estar na vida (FARIA, 2016).

Como corrobora Alberti et al. (2003, p. 19) “[...] o que norteia o uso de drogas está relacionado com a estrutura clínica que é dada na singularidade de cada sujeito".

A toxicomania se apresenta então como efeito de um discurso, na medida em que rompe com o modelo médico vigente, no qual parece não haver sujeito em questão (MARCOS; TÓTOLI, 2017). “O toxicômano é então, para a psicanálise, um significante identificatório do sujeito. Situar a toxicomania no campo da psicanálise é admitir a existência de um fenômeno bem caracterizado, sem, no entanto, caracterizá-la como um conceito" (MARCOS; TÓTOLI, 2017, p. 129). Isso porque, para a psicanálise, a relação sujeito-droga importa mais do que qualquer conceituação desse fenômeno (MARCOS ;TÓTOLI, 2017). Segundo Marcos e Tótoli (2017, p. 129):

Para abordar o conceito de toxicomania, a partir da psicanálise, como efeito de um discurso, é imprescindível explicitar como o sujeito se relaciona com o Outro para então compreendermos a posição do sujeito toxicômano em relação a este Outro.

Conclui-se, então, que todas as formas de intoxicação podem ser consideradas uma resposta não sintomática, marca de um sujeito que tenta anular sua divisão primordial, ignorando tudo que venha do inconsciente (MARCOS; TÓTOLI, 2017).

\section{Que estrutura?}

Agora que já situamos a toxicomania no campo da psicanálise, podemos partir para as questões estruturais que cercam esse fenômeno. Segundo o que Alberti et al. (2003) confirmaram em estudo, nos últimos quinze anos, a toxicomania foi abordada basicamente 
por duas vertentes do saber psicanalítico. A primeira caracteriza este fenômeno exclusivamente como um tipo clínico da perversão e a outra o considera suscetível de se apresentar em qualquer uma das três estruturas clínicas previstas pela psicanálise.

Trabalharemos com a vertente que considera a toxicomania um fenômeno passível de ocorrência tanto na psicose como na neurose e na perversão. Alberti et al. (2003) afirmam que, para a clínica psicanalítica, um fenômeno não pode jamais determinar a estrutura. As relações que cada sujeito estabelecerá com a droga serão sempre meios singulares de lidar com o mal-estar, o desprazer, enfim, a castração. As autoras afirmam ainda:

a importância das entrevistas preliminares no deciframento da estrutura clínica dos sujeitos usuários de drogas, o que será fundamental para o processo de análise. O importante é ater-se ao discurso do sujeito, poder escutá-lo, e não estabelecer a regra de que todo toxicômano é perverso. Ser toxicômano, por si só, não diz nada do sujeito (ALBERTI et al., 2003, p. $18)$.

Identificar o processo de singularização - e o modo como cada sujeito se inscreve nas estruturas psíquicas, independentemente se há ou não o consumo de drogas - só se faz possível através de um exame estrutural feito a partir da relação deste processo com a castração. Neurose, psicose e perversão são as estruturas que surgem como respostas ao enigma da castração (ALBERTI et al., 2003).

Tendo em vista esta orientação, Alberti et al. (2003, p. 24). levantam a possibilidade da toxicomania se caracterizar como um sintoma neurótico. Afirmam que:

A concepção freudiana de um sujeito do inconsciente, atormentado pelo sexo, pela morte e pela interdição, foi substituída pela concepção psicológica de um indivíduo depressivo, que rechaça o inconsciente, evitando o conflito.

Sendo assim, esse indivíduo seria uma espécie de versão atual do histérico, que recorreria às drogas buscando o ideal de uma felicidade total, capaz de apaziguar o mal-estar sentido (ALBERTI et al., 2003). As autoras Marcos e Tótoli (2017, p. 136) declaram que:

É importante ressaltar que o recurso à droga, independente da estrutura psíquica, refere-se à posição do sujeito com relação ao Outro e ao gozo, mas a função do objeto droga se difere em cada estrutura, pois o gozo extraído do objeto não é o mesmo.

Haveria então uma diferenciação no modo como a droga se presentifica na dinâmica de cada estrutura. Nas palavras das autoras: 
Na neurose, a droga pode promover uma ruptura com o gozo fálico, sem que haja a foraclusão do Nome-do-Pai, permitindo ao sujeito experimentar um novo tipo de gozo, um gozo cínico que rechaça o Outro, que recusa que o próprio gozo do corpo seja metaforizado. É uma forma de desviar o desejo do Outro, da castração do Outro, através de um curto-circuito. Já, na psicose, a droga não promove essa ruptura com o gozo fálico, à medida que ela é dada de antemão, pois já existe a foraclusão (MARCOS; TÓTOLI, 2017, p. 136).

Na perversão, segundo Alberti et al. (2003) a droga serviria como um instrumento de defesa contra uma possível psicotização, uma vez que a perversão se formaria antes de uma estruturação neurótica. As autoras indicam:

Assim, a saída toxicômana consistiria na renúncia às libidinizações primitivas por meio da droga ou do fetiche. Saída fetichista, que conservaria as taxas de realidade em todos os domínios, exceto naquilo que diz respeito ao fetiche, para o perverso, ou à droga, para o toxicômano (ALBERTI et al., 2003, p. 17).

\section{Gozo}

Santiago (2001) nos traz a concepção Lacaniana da dimensão ética do gozo, hipótese pela qual ele aborda a toxicomania, que seria uma consequência direta da materialização do efeito real da ciência sobre o corpo. Para ele, "abordar a toxicomania sob o ponto de vista ético do gozo do corpo, como sugere Lacan, em Psicanálise e medicina, leva, certamente, a concebê-la como um modo particular de satisfação, distinta da dependência biológica" (2001, p. 31).

O conceito de gozo está relacionado com a lei, podendo ser uma relação de desafio, submissão ou desdém (LEMOS, 2004).

Como Almeida aponta "O emprego do conceito de gozo acha-se enraizado no Seminário 7 - A ética da Psicanálise (LACAN, 1988), no qual é definido como curta e tripudiada satisfação de uma pulsão" (2010, p. 72).

Essa satisfação exige um preço, nesse sentido o autor vai dizer que "o exercício do gozo engloba algo da ordem de uma dívida simbólica" (ALMEIDA, 2010, p. 73). A culpa é o que revela essa dívida no registro do imaginário. A transgressão contrapõe a proibição, entretanto, implica o reconhecimento da lei.

O gozo absoluto, sem limites, é mítico e pertence à pulsão de morte. $\mathrm{O}$ único gozo que nos é acessível está integrado ao significante fálico, que representa a inexistência da relação sexual que barra o gozo (ALMEIDA, 2010). O autor recorre a Lacan ao afirmar que o 
desejo "não é apenas a representação sexual e imaginária de uma perda, mas uma forma encontrada pelo sujeito de se identificar com a perda. O gozo comparece como aquilo que, supostamente, preencherá essa falta" (ALMEIDA, 2010, p. 77).

O toxicômano seria um sujeito que se nega a participar do gozo universalizado da civilização, o gozo fálico, aquele que se reafirma nas relações de poder, dinheiro e competição social. Ele se mantém à margem dessas relações, recusando o gozo fálico e aderindo a um gozo mortífero. Nas palavras da autora, "Na toxicomania, o sujeito rompe com as relações sociais e casa com a droga" (LEMOS, 2004, p. 54).

O agravamento no quadro das toxicomanias em nossa sociedade, revela o triunfo do gozo não metaforizado - aquele que não é regido pelo significante - produtor do sujeito “assujeitado", que se tornou um escravo subjugado pelo seu objeto de gozo (LEMOS, 2004).

Uma das leituras possíveis afirma que: “O sucesso da droga na pós-modernidade deve ser concebido no contexto de declínio do nome-do-pai, do declínio acentuado do pai simbólico. O rompimento do toxicômano com o gozo fálico remete, inevitavelmente, à metáfora paterna" (LEMOS, 2004, p. 56). Esse declínio revela outro, o da produção dos significantes mestres, significantes que produzem o sujeito. Logo, com a escassez de significantes, a capacidade de fantasiar fica limitada. Considerando que a fantasia é responsável por reduzir o gozo, tal limitação acaba impulsionando-o, provocando um empuxo ao gozo. A substância serviria então, a uma busca pela completude, tentando evitar a falta que se tornou insustentável (LEMOS, 2004).

Em relação ao tratamento, Lemos afirma que os desafios começam já na transferência, em que a instauração de uma relação que possibilite uma estruturação narcísica se faz necessária. A formação de uma triangulação simbólica capaz de operar como função paterna é o objetivo do tratamento. É preciso promover um deslocamento do gozo no real do toxicômano. Imergindo-o em devaneios fantasísticos, provocando alternativas de prazer, por meio de uma ordem cultural que cumpra com a metáfora da castração simbólica (2004).

Para tanto, o analista deve operar junto ao sujeito na construção de suas fantasias, barrando o empuxo ao gozo (LEMOS, 2004).

\section{O objeto droga}

Como aponta Faria (2016), os efeitos químicos que a droga causa no corpo, provocando novas sensações, alterando a percepção e a consciência, podem levar esse corpo ao colapso. A morte pode estar, por vezes, no horizonte e no limite da relação que o 
toxicômano estabelece com a substância, isso porque existe um real em jogo nesta relação, o que não pode ser negligenciado.

Segundo Lemos (2004, p. 53): “As drogas atuam como uma nova forma de responder ao sofrimento. O toxicômano é aquele que não quer saber, que não se submete a nenhum interdito, que se inscreve em um mais-de-gozar absoluto". A promessa de uma felicidade absoluta é representada para o sujeito pelo objeto-substância, que se configura como uma substância real (MARCOS; TÓTOLI, 2017). Santiago (2001, p. 31) irá dizer que:

Se a droga pode servir à satisfação, isso acontece porque esta última está aberta, por sua natureza mesma, a toda espécie de saída possível. A abordagem clínica propriamente lacaniana da droga sustenta-se no fato de que a pulsão pode se satisfazer com um objeto nocivo ao indivíduo.

Lemos (2004) compara a droga com a religião, ao afirmar que ambos seriam efeitos do desamparo infantil diante da substituição da autoridade paterna. Ela vai dizer que a relação do jovem contemporâneo com a lei é a questão em jogo e cita Freud quando diz que a relação de uma pessoa com Deus depende da sua relação com o pai, pois Deus seria a imagem de um pai glorificado.

Por conseguinte, a autora indica que se deve "investigar a raiz neurótica dessa 'angústia do pai'. Parte da raiz da delinquência juvenil está assentada sobre essa reminiscência neurótica do desamparo original.” (LEMOS, 2004, p. 57). Uma transformação na economia do gozo estaria sendo operada, uma vez que tal delinquência, expressada por vezes na toxicomania, não responderia apenas como uma questão singular, mais estaria se tornando também um fenômeno social (LEMOS, 2004).

Santiago (2001, p. 29) afirma que: "Atualmente, a ciência fornece operadores químicos capazes de se constituir em reguladores da própria economia libidinal, cuja única finalidade é extrair satisfação no nível do corpo". Tais operadores se configuram como objetos da ciência, feitos para que o sujeito possa gozar deles, produzindo um efeito real que escapa ao cientista. Isso, porque a ciência além de fabricá-los, encontra um meio de manter o desejo do sujeito ligado a esses objetos (SANTIAGO, 2001).

O surgimento da ciência carrega como aspecto crucial, não o fato de ter introduzido no mundo um conhecimento mais aprofundado e ampliado, e sim o de ter feito emergir, no real, coisas que não havia antes, no nível da percepção humana (SANTIAGO, 2001). Assim, Santiago (2001, p. 27) afirma que: "Portanto, a singularidade da interpretação lacaniana das incidências da ciência no corpo visa, especialmente, a isolar o elemento real desses efeitos". 
O saber científico, a partir dessa interferência, não possibilita somente o acesso ao real, mas também o determina e transforma-o, inserindo nele objetos que, segundo o autor, são candidatos a se tornarem restos, resíduos da civilização. Esses objetos foram denominados por Lacan de gadgets, exprimindo o sentido de dejeto que marca sua presença no mundo (SANTIAGO, 2001). Santiago (2001, p. 28) nos diz que:

Esses gadgets qualificam todas as espécies de instrumentos que, desde então, fazem parte da existência humana, sendo que o lado fortemente utilitarista desses objetos é o fator que viabiliza o enfoque conceitual da ciência como discurso, portanto, como um dispositivo de saber que produz laço social.

Nesse sentido, Almeida (2010, p. 74) afirma que: "O sentido do utilitarismo dos objetos de gozo, dos objetos que pertenceriam a outros, ou seja, do direito ao gozo apela à questão do gozo em sua relação com o semelhante, visto que situa o gozo no campo do outro e com a lei”.

Segundo Marcos e Tótoli (2017), o gozo experimentado na toxicomania é sempre idêntico a si mesmo, não existindo alteridade. Tudo que ocorre é a demanda infinita pela droga, objeto de consumo, fazendo com que a prática do gozo se reduza a uma prática pulsional. O sujeito entra num círculo vicioso, desejando sempre a mesma Coisa, objeto de desejo no qual a droga se transformou.

Lemos (2004) infere que o gozo do toxicômano é um gozo cínico, que se dá indissociável do próprio corpo, não passando pelo corpo do Outro, tornando-se cínico por gozar à revelia deste Outro. A autora formula que:

No totalitarismo narcísico, somente eu posso gozar mais de tudo e de todos. A droga mercadoria deve ser consumida como um gadget, um produto fashion. Nas relações interpessoais, como nas econômicas, o ideal consumista se sustenta na crença de um objeto sempre disponível, passível de ser adquirido sem interdito, num gozo absoluto (LEMOS, 2004, p. 55).

Assim, a atual imagem do gozo estaria desprovida do simbólico. O cinismo contemporâneo estaria preso ao gozo individual, com cada um querendo manter o seu, sem se preocupar se é subversivo ou não (LEMOS, 2004).

Santiago (2001) conclui que a intensa adesão do toxicômano à droga só pode ser explicada pela concepção de um corpo submetido à ação do significante e inseparável do gozo. É como uma tentativa de enfrentar as perturbações do corpo que alguns sujeitos optam por esse modo de satisfação. Logo, "diante do corpo inseparável do gozo, a toxicomania 
poderia ser vista como um mais-gozar particular, correlativo a uma mudança operada, pela ciência, no real" (SANTIAGO, 2001, p. 31).

A função de mais-de-gozar pode ser verificada com a introdução da droga no campo do gozo, por meio de um excesso de satisfação, em que o objeto se institui como parceiro essencial e exclusivo do sujeito. Tal função se vincula com a captura do objeto na satisfação pulsional, e consequentemente, com a recuperação da perda (ALMEIDA, 2010).

\section{Considerações finais}

A realização desta pesquisa objetivou levantar os fundamentos teóricos da psicanálise relacionados ao fenômeno da toxicomania. Buscou-se respostas para questões referentes à aplicabilidade da psicanálise neste campo. Para tanto, os textos selecionados para a elaboração desta revisão foram de suma importância.

Verificou-se que o termo toxicomania equivale, para a psicanálise, a um significante identificatório para os sujeitos que fazem do consumo de drogas sua medida paliativa. Medida que assumem para lidar com o mal-estar, inerente a vida humana. Destaca-se a primazia dada à singular relação que cada sujeito estabelece com o objeto droga. Condição básica para abordar a toxicomania via psicanálise, pois, independente da estrutura psíquica, a droga terá uma função específica em cada caso.

Outro importante ponto, a ser destacado, é a relação direta que o conceito lacaniano de gozo mantém com a toxicomania. Constantemente encontrado nos textos referidos, ficou evidente a importância que tal conceito possui para o entendimento do fenômeno pesquisado. Assim como ficou evidente a necessidade de um aprofundamento neste campo, tão extenso e tão complexo.

Por fim, pôde-se constatar que existem resistências em relação à atuação de psicanalistas na área da toxicomania. De um lado, tais resistências podem aparecer por parte dos psicanalistas, os quais se afastam desta área, acabando por relegar a toxicomania a abordagens mais comportamentais e/ou farmacológicas.

Por outro lado, os próprios toxicômanos, não estão inclinados a buscar a análise como primeira alternativa na procura de tratamento. Ainda assim, a psicanálise tem muito a oferecer e pode contribuir de forma incisiva no tratamento dos toxicômanos. Para tanto é preciso que construções sejam empreendidas a partir da psicanálise, uma vez que este referencial enxerga para além do toxicômano, um sujeito, e se propõe a operar junto a ele. Como Alberti et al. (2003, p. 26) concluem, para que isso seja feito é necessário “[...] colocar esse sujeito a 
trabalho com todo sofrimento que ele fizera equivaler à droga, o que exige a presença do analista e de seu ato a apostar no desejo, irrestritamente, intransigentemente até mesmo para o analista".

\section{REFERÊNCIAS}

ALBERTI, S.; INEM, C. L.; RANGEL, F. C. Fenômeno, estrutura, sintoma e clínica: a droga. Rev. Latino Americana de Psicopat. Fund., n. 3, p. 11-29, 2003.

ALMEIDA, A. R. B. Toxicomanias: uma abordagem psicanalítica. Cap. II. Salvador: EDUFBA; CETAD/UFBA, 2010. p. 69-108.

ELIA, L. Psicanálise: clínica \& pesquisa. In: ALBERTI, S.; ELIA, L. (Orgs). Clínica e Pesquisa em Psicanálise. Rio de Janeiro: Rios Ambiciosos, 2000. p. 19-35.

FARIA, M. W. A especificidade da toxicomania. Pharmakon, v. 2, p. 54-57, 2016.

FREUD, S. O mal-estar na civilização. In: FREUD, S. Edição Standard Brasileira das Obras Completas de Sigmund Freud. v. 21. Cap. 2. Rio de Janeiro: Imago, 1974 [1930]. p. 47-53.

LACAN, J. O seminário, livro 7: a ética da psicanálise, 1959-1960. Rio de Janeiro: Jorge Zahar Editor, 1988.

LEMOS, I. O gozo cínico do toxicômano. Mental, Barbacena, v. 2, n. 3, p. 51-60, 2004.

MARCOS, C. M.; TÓTOLI, F. C. Psicanálise e Toxicomania: o gozo da droga e a ruptura com o gozo fálico. Cad. Psicanál. (CPRJ), Rio de Janeiro, v. 39, n. 36, p. 125-140, 2017.

SANTIAGO, J. Lacan e a toxicomania: efeitos da ciência sobre o corpo. Ágora, v. 4, n. 1, p. 23-32, 2001.

\section{Como referenciar este artigo}

LAMEGO, R. G. J.; BRITO, L. C. Toxicomania: a droga, o sujeito e a psicanálise. Doxa: Rev. Bras. Psico. e Educ., Araraquara, v. 22, n. esp. 1, p. 284-298, out., 2020. e-ISSN: 25948385. DOI: https://doi.org/10.30715/doxa.v22iesp.1.14134

Submetido em: 20/04/2020

Revisões requeridas: $15 / 06 / 2020$

Aprovado em: 20/08/2020

Publicado em: 30/09/2020 